\title{
MANAGING YOUNG PEOPLE'S TALENTS AND THEIR DEVELOPMENT IN MODERN MANAGEMENT ${ }^{1}$
}

\author{
Mariya F. Mizintseva \\ All-Russian Institute for Scientific and Technical Information of the Russian Academy of Sciences, \\ Moscow, Russian Federation \\ Anna R. Sardaryan \\ All-Russian Institute for Scientific and Technical Information of the Russian Academy of Sciences, \\ Moscow, Russian Federation \\ Mariya A. Chugrina \\ All-Russian Institute for Scientific and Technical Information of the Russian Academy of Sciences, \\ Moscow, Russian Federation
}

\begin{abstract}
The article examines key problems and trends in functioning of talent management systems in the modern business environment. The authors give a brief history of the emergence of talent management as a personnel technology, a brief review of literature on the subject, investigate the main characteristics of a talented employee. In addition, the article presents the author's research, the purpose of which was to identify the most pronounced talents among young people, as well as to study the necessary directions in the development of talents, according to young people. The study was attended by 350 students, including already working undergraduate students who are employees of Russian companies. As a result, it was revealed that the today's youth often discover their talents in the field of sports, public speaking, learning foreign languages, entrepreneurship, etc. The main directions of modern young people's talent development are the following: organizing scientific and creative activities for young people; participating in international intellectual, creative and sports competitions; creating conditions for training of young employees, etc. The authors note that the process of the talent development and management should be systematic and based on "school - university - employment - training" continuity.

Key words: talent management, human resources management, HiPo employees, globalization of business, human resources management, youth, young employees.

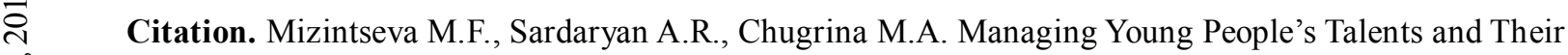
$\therefore$ Development in Modern Management. Journal of Volgograd State University. Economics, 2019, vol. 21, no. 4,

\section{УПРАВЛЕНИЕ ТАЛАНТАМИ И ИХ РАЗВИТИЕ У МОЛОДЕЖИ} В СОВ РЕМЕННОМ МЕНЕДЖМЕНТЕ ${ }^{1}$
\end{abstract} $\sum \mathrm{pp}$

\section{Мария Федоровна Мизинцева}

Всероссийский институт научной и технической информации РАН, г. Москва, Российская Федерация

\section{Анна Романовна Сардарян}

Всероссийский институт научной и технической информации РАН, г. Москва, Российская Федерация 


\section{Мария Александровна Чугрина}

Всероссийский институт научной и технической информации РАН, г. Москва, Российская Федерация

Аннотация. В статье рассмотрены ключевые проблемы и тенденции функционирования систем управления талантами в современной бизнес-среде. Приводится краткая история возникновения управления талантами как кадровой технологии, дается краткий обзор литературы по данной тематике, определяются основные характеристики талантливого сотрудника. Кроме того, в статье приведено авторское исследование, цель которого заключается в выявлении наиболее выраженных талантов среди молодежи, а также необходимых направлений в развитии талантов, согласно опросу студентов. В исследовании приняло участие 350 студентов, в том числе уже работающих в российских компаниях студентов-магистрантов. В результате было выявлено, что современная молодежь чаще всего обнаруживает свои таланты в сфере спорта, ораторского мастерства, изучения иностранных языков, предпринимательства и пр. В качестве основных направлений развития талантов у современных молодых людей выделяются: организация для молодежи научных и творческих мероприятий; участие в международных интеллектуальных, творческих и спортивных соревнованиях; создание условий для повышения квалификации молодых сотрудников и пр. Отмечается, что процесс развития талантов и управления ими должен носить системный характер и основываться на преемственности «школа - вуз - трудоустройство - повышение квалификации».

Ключевые слова: управление талантами, кадровый менеджмент, НіРо-сотрудники, глобализация бизнеса, управление человеческими ресурсами, молодежь, молодые сотрудники.

Цитирование. Мизинцева М. Ф., Сардарян А. Р., Чугрина М. А. Управление талантами и их развитие у молодежи в современном менеджменте // Вестник Волгоградского государственного университета. Экономика. -2019. - Т. 21, № 4. - С. 162-170. - DOI: https://doi.org/10.15688/ek.jvolsu.2019.4.16

\section{Введение}

Управление талантами как направление в кадровом менеджменте современных компаний появилось сравнительно недавно - в 90-е гг. прошлого столетия. За прошедший период данное направление расширилось, стало прочно развиваться в управлении современной компанией, а термин «война за таланты» вошел в обиход и стал важнейшей тенденций в управлении человеческими ресурсами в последние годы. Появление и расширение границ «войны за таланты» связано с рядом причин: процессы глобализации бизнеса, снижение лояльности к одной компании со стороны талантливых сотрудников, актуализация поиска уникальных сотрудников с компетенциями в узкоспециализированных направлениях и пр. Так, согласно исследованиям специалистов консалтинговой компании «McKinsey», в 1900 г. работники умственного труда требовались лишь для $17 \%$ рабочих мест, а сейчас - для более чем 60 \%. Таким образом, самые яркие работники создают значительно большую сравнительную ценность для современной компании [Майклз и др., 2005].

Термин «управление талантами» появился в 1998 г. в статье Д. Уоткинса, а в конце 1990-х гг. компания «McKinsey» опубликова- ла отчет «Война за таланты», в котором говорится, что «война за таланты - стратегический переломный момент, который еще не замечают многие компании, но она станет определяющей чертой делового мира на много лет вперед. Временный спад в экономике не изменит необратимые тенденции спроса на высокоталантливых людей. Война за таланты - это вызов для всех компаний. Но для тех, которые будут реагировать активно и оперативно, это еще и огромная возможность создать конкурентное преимущество» [Майклз и др., 2005]. Прогнозируется, в что ближайшее время на рынке труда особой ценностью будут обладать уникальные работники - те люди, которые станут носителем уникальных компетенций и каких на отечественном рынке труда будет не так много. Все активней в России и в мире будет расти спрос на интеллект, нестандартные способности и умения [Мизинцева и др., 2017, с. 3642].

К сегодняшнему дню в научной литературе накоплен определенный пласт теоретических положений касательно управления талантами. Можно выделить таких зарубежных исследователей, занимавшихся управлением талантами в менеджменте современных организаций, как N. Chhabra, A. Mishra [Chhabra 
et al., 2008], М. Орт, М. Эффрон [Орт и др., 2014], А. Робертсон, Г. Эбби [Робертсон и др., 2004], Т.Дж. Питерс [Питерс, 2006], Х. Хэндфилд-Джонс, Э. Экселрод [Хэндфилд-Джонс и др., 2011], N. Dries [Dries, 2013], U. Hana, V. Lucie [Hana et al., 2015], M.C. Meyers, M. Van Woerkom [Meyers et al., 2013], S. Swailes, Y. Downs, K. Orr [Swailes et al., 2014].

Среди российских авторов вопросы управления талантами с различных точек зрения исследовали С. Иванова, Д. Белдогоев [Иванова и др., 2018], Д. Марыскин [Марыскин, 2017], Е.П. Ильин [Ильин, 2010], Н. Черепухина, Ю. Наврузов [Искусство..., 2002] и др.

Однако приходится констатировать тот факт, что исследований в данной области все еще недостаточно, в том числе не выработан единый понятийный аппарат, нет расширенной классификации талантов личности, не изучены аспекты успешной стратегии развития талантов сотрудников (в частности, отдельно по половозрастным категориям), профессиональной деятельности, сфер деятельности компаний, а также нет системы развития талантов у лиц с ограниченными физическими возможностями. Особенно важным, на наш взгляд, является вопрос развития талантов у молодежи, аспекты которого в научной литературе остаются также все еще малоизученными.

\section{Ключевые подходы к управлению талантами}

В процессе развития управления талантами как направления в менеджменте современных компаний сложилось два противоположных подхода к выявлению и развитию талантов. Так, первый, инклюзивный подход подчеркивает, что талант является развиваемым и его можно развить даже у тех индивидов, которые ранее не демонстрировали выдающихся результатов. Второй подход, эксклюзивный, делает акцент только на поиске высокоэффективных сотрудников с экстраординарными способностями. Этот подход, который первым возник в талант-менеджменте, основывается на сегментации персонала (разделении его на определенные группы в зависимости от индивидуального потенциала) и развитии только высокопотенциальных сотрудников (HiPo - High Potential). Как правило, в такую категорию сотрудников входит не более $10 \%$ персонала.

Талантливыми работниками могут считаться те работники в компании, которые регулярно демонстрируют свои исключительные достижения и дальнейший потенциал развития. В практике передовых компаний талантливых сотрудников делят на 3 категории:

- «высокопотенциальные сотрудники» (High Potential - Hi-Po) - сотрудники, peгулярно генерирующие новые идеи и обладающие высоким потенциалом для развития в будущем (по оценкам ряда специалистов такие сотрудники встречаются 1 на 1000 и более работников, что существенно затрудняет их поиски);

- «Stars», или «Звезды»», - узкоспециализированные специалисты, обладающие уникальными компетенциями;

- групnа «VIP» - талантливые руководители (сотрудники, обладающие управленческим интеллектом, лидерскими способностями, способные вести за собой и вдохновлять).

И хотя сегодня в научной литературе не представлено единого определения «талантливый сотрудник», а также не существует универсального набора характеристик, которые бы описывали «талантливого работника», тем не менее можно выделить типичные особенности, присущие талантам, среди которых: высокая результативность работы, совпадающие с компанией ценности, новаторство, обучаемость, наличие профессионального и социального опыта, гибкость в принятии решений, умение налаживать эффективные коммуникации, командный дух и пр.

\section{Исследование талантов среди молодежи}

Авторами данной публикации была предпринята попытка исследовать наиболее часто встречающиеся виды талантов среди современной молодежи. Так, в 2018 г. на кафедре менеджмента экономического факультета РУДН (RUDN University) было проведено исследование современного состояния управления талантами и перспектив развития данного направления. В опросе приняло участие 350 студентов, в том числе уже работающих студентов-магистрантов, являющихся сотруд- 
М.Ф. Мизинцева, А.Р. Сардарян, М.А. Чугрина. Управление талантами и их развитие у молодежи

никами российских компаний. Опрос проводился по специально разработанной авторской анкете (рис. 1). Участникам предлагалось самостоятельно оценить себя и указать, какими талантами они обладают в большей степени, а также определить наиболее эффективные, на их взгляд, методы развития талантов.

В анкете были предложены различные виды талантов, а респондентам предлагалось выбрать не более 3 вариантов талантов, которые, по мнению опрашиваемых, у них являлись наиболее развитыми. Так, самыми встре- чающимися видами талантов среди молодежи оказались следующие: спортивные способности $(9,9 \%)$, способность к изучению иностранных языков $(8,6 \%)$, предпринимательские способности $(8,6$ \%) (см. таблицу).

Необходимо отметить, что почти все участники исследования выделяли у себя сразу несколько талантов в различных областях (2-3 вида) и лишь незначительная часть респондентов указывала наличие только одного вида таланта. Это еще раз позволяет сделать вывод, что при наличии потенциала человек

\begin{tabular}{|c|c|c|}
\hline \multicolumn{3}{|c|}{$\begin{array}{l}\text { Уважаемый респондент! } \\
\text { Просим Вас принять участие в нашем опросе «Управление талантами». } \\
\text {... } \\
\text { Как Вы считаете, какие методы развития талантов наиболее эффективны сегодня } \\
\text { (отметьте не более } 5 \text { вариантов)? }\end{array}$} \\
\hline 1 & Наставления и контроль родителей & \\
\hline 2 & Секции и кружки в школе & \\
\hline 3 & Чтение книг по развитию талантов & \\
\hline 4 & Мастер-классы от специалистов в своей отрасли & \\
\hline 5 & Видеотренинги и дистанционное обучение (развитие) & \\
\hline 6 & Деловые игры & \\
\hline 7 & Только самомотивация & \\
\hline 8 & Другое & \\
\hline
\end{tabular}

Рис. 1. Фрагмент анкеты «Управление талантами»

Примечание. Составлено авторами.

Распространенность талантов среди молодежи, \%

\begin{tabular}{|c|l|c|}
\hline $\begin{array}{c}\text { № } \\
\text { п/п }\end{array}$ & \multicolumn{1}{|c|}{ Виды талантов } & $\begin{array}{c}\text { Среди всех } \\
\text { респондентов }\end{array}$ \\
\hline 1 & $\begin{array}{l}\text { Музыка (игра на музы- } \\
\text { кальных инструментах) }\end{array}$ & 4,9 \\
\hline 2 & Музыка (вокал) & 6,2 \\
\hline 3 & Живопись & 4,9 \\
\hline 4 & Ораторское мастерство & 6,2 \\
\hline 5 & Спорт & 9,9 \\
\hline 6 & Кулинария & 8,6 \\
\hline 7 & Танцы & 7,4 \\
\hline 8 & Поэзия & 0,0 \\
\hline 9 & Проза & 0,0 \\
\hline 10 & Рукоделие и шитье & 4,9 \\
\hline 11 & Боевые искусства & 1,2 \\
\hline 12 & Иностранные языки & 8,6 \\
\hline 13 & Фотография & 4,9 \\
\hline 14 & Организация своего дела & 8,6 \\
\hline 15 & Воспитание детей & 6,2 \\
\hline 16 & Политика & 2,5 \\
\hline 17 & Наука & 6,2 \\
\hline 18 & Психология & 3,7 \\
\hline
\end{tabular}

Примечание. Составлено авторами. 


\section{УПРАВЛЕНИЕ ЭКОНОМИЧЕСКИМ РАЗВИТИЕМ}

может развиваться и добиваться результатов в совершенно разных областях. А результативность, в свою очередь, демонстрирует, что человек обладает не только потенциалом, но и терпением, силой воли, самодисциплиной и другими качествами, необходимыми для достижения целей.

Среди студентов мужского и женского пола таланты в большей степени развиты в различных областях. У мужчин таланты в большей степени проявляются в таких сферах, как ораторское мастерство (13\%), спорт (13\%) и организация своего дела (13\%) (рис. 2).

Женщины наиболее талантливы в вопросах воспитания детей (9\%), иностранных языков (9\%), кулинарии (9\%), спорта (9\%). Примечательно, что среди женщин таланты во всех областях распределяются практически равномерно (рис. 3). Среди мужчин, наоборот, наиболее ярко выражены только основные сферы (см. рис. 2).

Большая часть опрашиваемых $(80 \%)$ отметила, что развивать их таланты начали еще родители в детстве. Однако $20 \%$ опрашиваемых ответили, что родители абсолютно не уделяли внимания этому вопросу или занимались развитием талантов недостаточно.

Среди современных методов управления талантами наиболее эффективными, по мнению всех опрошенных молодых людей, являются секции и кружки в школе (18 \%), мастер-классы от специалистов в своей области (17\%), самомотивация (17 \%) (см. рис. 4). Высокая эффективность секций и кружков в школе во многом объясняется системным подходом к обучению и развитию определенных навыков и способностей.

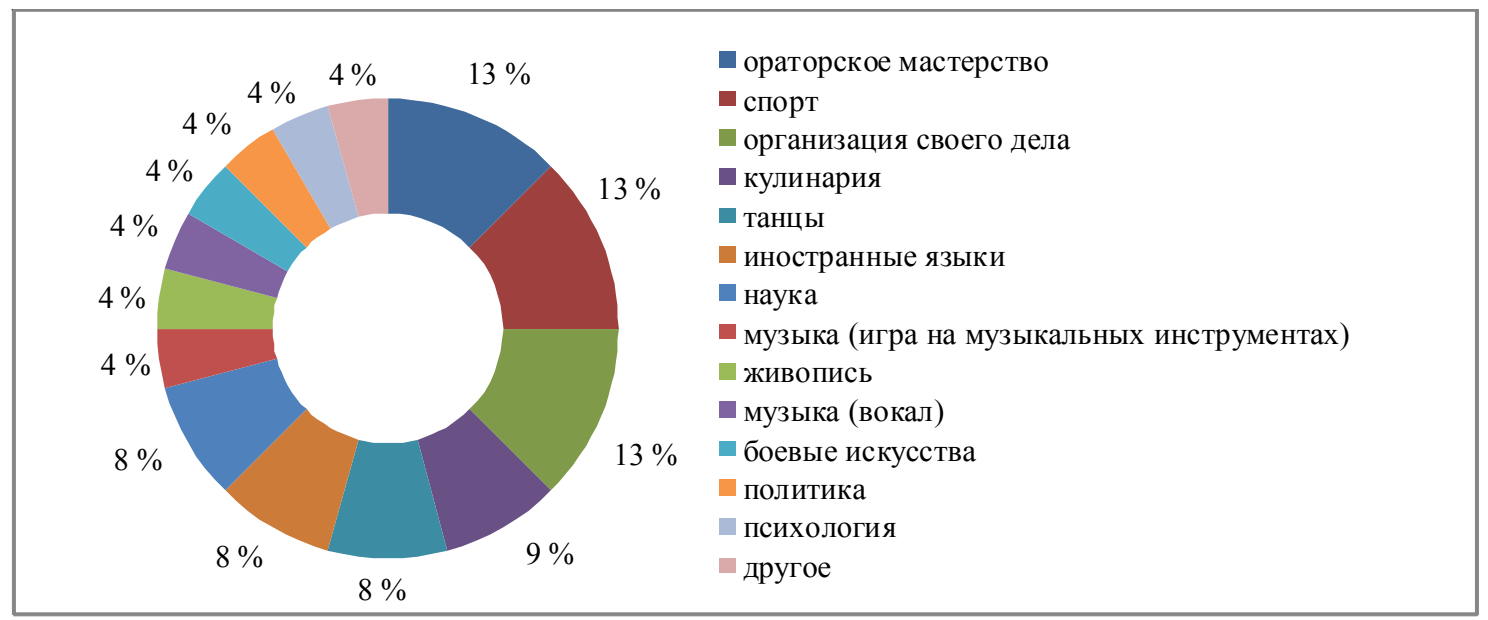

Рис. 2. Популярные таланты среди студентов мужского пола

Примечание. Составлено авторами.

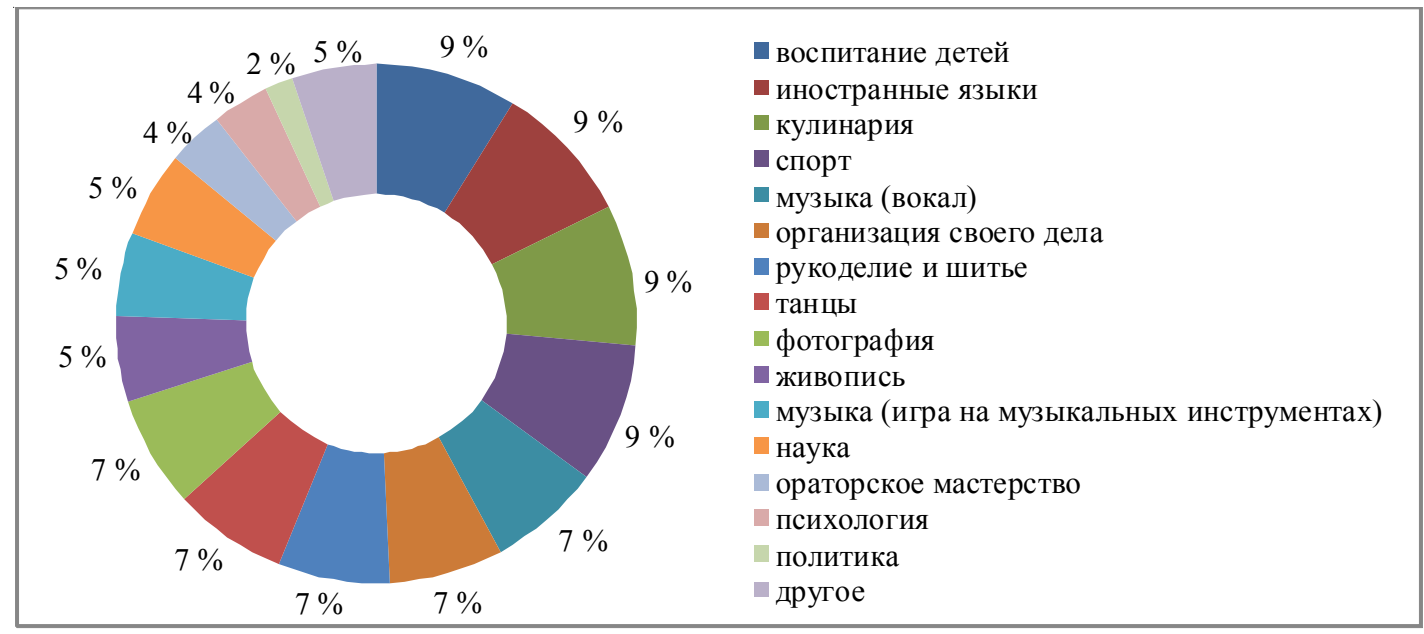

Рис. 3. Популярные таланты среди студентов женского пола

Примечание. Составлено авторами. 


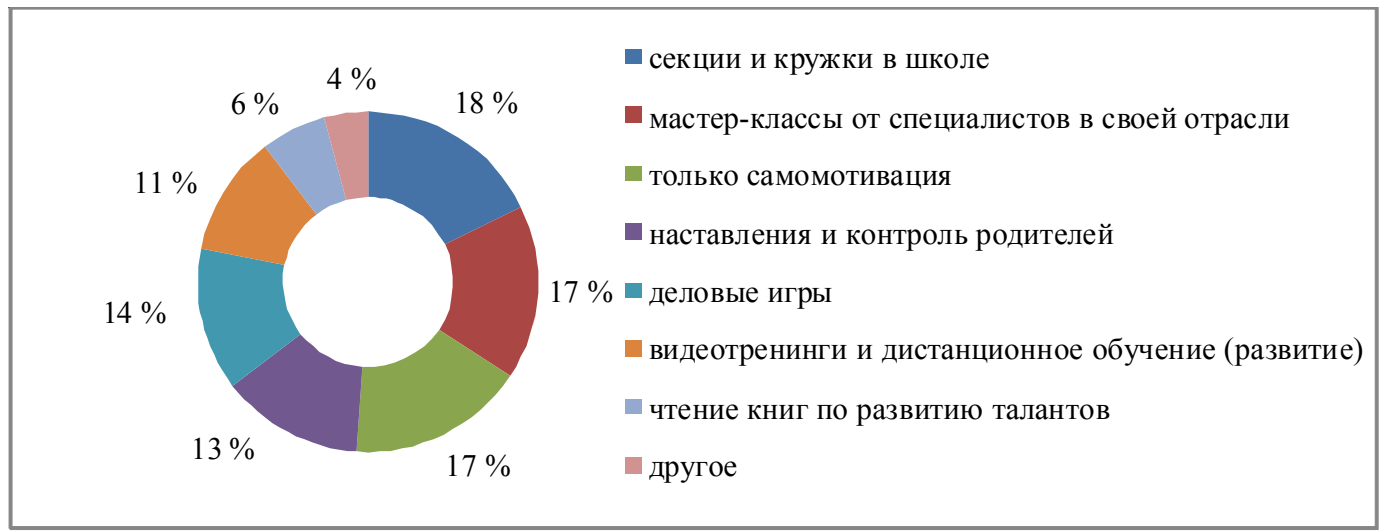

Рис. 4. Наиболее эффективные методы развития талантов

Примечание. Составлено авторами.

Завершая обучение в школе, большинство молодых людей перестает систематически заниматься развитием какого-либо навыка, переводя такие занятия в категорию «хобби» и откладывая все чаще занятия «на потом». Развитие определенных навыков, которые проявляются уже в раннем или в подростковом возрасте, перерастая порой из различных увлечений в профессиональную деятельность, в большинстве случаев зависит от самого человека и главным образом определяется самомотивацией человека. Отсутствие системного подхода и должного внимания со стороны преподавателей вузов, специалистов в определенной профессиональной области, государства к вопросам поддержки молодежи приводит к тому, что молодые люди испытывают трудности в выявлении и развитии талантов, сдерживая и откладывая их проявление.

Большая часть респондентов (57\%) в ходе опроса отметила, что современные компании и вузы в настоящее время уделяют недостаточно внимания вопросам развития и управления талантами.

\section{Основные направления развития талантов у современной молодежи}

Основной целью управления талантами является планомерное содействие повышению эффективности компании в постоянно меняющейся бизнес-среде. Для ее достижения необходимо наличие в организации определенной системы управления талантами, включающей, как правило, следующие элементы: планирование (Talent Demand), привлечение и найм (Attraction and Recruiting Strategy), адаптация / развитие (Development), оценка (Perfomance Management), обучение и планирование карьеры (Succession \& Career Planning), вознаграждение (Rewarding) и удержание (Retention). При построении системы управления талантами в современных организациях необходимо обращать внимание не только на уровень компетентности и результативности, но и на потенциал сотрудника, поскольку способность расти и развиваться один из признаков таланта. Особенно важно это учитывать для молодых сотрудников, которые еще в силу возраста не успели развить необходимые профессиональные навыки и продемонстрировать высокую результативность в работе. Однако наличие потенциала и своевременное его выявление может стать ключевым аспектом дальнейшей эффективности не только отдельного сотрудника, но и всей компании в целом.

В настоящее время талантливые сотрудники должны обладать не только общепризнанными компетенциями в профессиональной среде, но и такими компетенциями, как системное мышление, межотраслевые коммуникации, работа с IT-системами, высокая адаптивность, кросс-культурность и открытость, профессиональное саморазвитие [Петроченко, 2018, с. 291].

Для того чтобы разработанная система управления талантами в компании была эффективна, она должна решать следующие задачи:

- своевременно выявлять способности одаренных сотрудников; 
- привлекать сотрудников различных уровней (начиная от стажеров и практикантов) к различным исследованиям в компании;

- обеспечивать целостность и преемственность в работе с одаренными сотрудниками на разных уровнях.

Главная цель взаимодействия с талантливой молодежью - активизировать работу, придав ей исследовательский, творческий характер, и, таким образом, передать молодым сотрудникам инициативу в организации своей познавательной деятельности и раскрытии своего потенциала.

В настоящее время к основным направлениям развития талантов у современной молодежи можно отнести следующие:

1) организация для молодых людей научных и творческих мероприятий;

2) участие молодежи в международных интеллектуальных, творческих и спортивных соревнованиях;

3) создание условий для повышения квалификации молодых сотрудников и стимулирование роста их профессионального мастерства;

4) открытие площадок для стажировок и ресурсных центров на базе лучших образовательных организаций и компаний - лидеров рынка в определенных областях;

5) внедрение современных технологий обучения (в том числе дистанционных), формирующих условия для выявления и развития способностей молодых сотрудников;

6) присуждение стипендий и премий талантливой молодежи, проявившей выдающиеся способности в различных областях;

7) поддержка конкурсов профессионального мастерства.

\section{Заключение}

В современных экономических условиях поиск и развитие талантливых молодых сотрудников становится основополагающим фактором эффективной работы компании и завоевания определенного места на рынке. Для организаций, ведущих свою деятельность в условиях внешней неопределенности, талантливые сотрудники выступают основным, а также одновременно труднодоступным (и не всегда выявленным) ресурсом для решения возникающих задач. Для того чтобы оставаться конку- рентоспособной организацией, необходимо заниматься не только мотивацией сотрудников, но и своевременным выявлением и развитием потенциала специалистов.

Проведенное исследование показало, что в настоящее время наиболее часто встречающимися видами талантов среди молодежи являются следующие: спортивные способности, способность к изучению иностранных языков, предпринимательские способности. Причем выявлять и развивать способности молодые люди начали еще обучаясь в школе, а для дальнейшего развития выявленных талантов необходимо было приложить много усилий и обладать значительной самомотивацией. В условиях бессистемного подхода или отсутствия должного внимания, поддержки и обратной связи со стороны преподавателей вузов, специалистов в определенной профессиональной области, государства молодежь испытывает трудности в выявлении и развитии талантов, сдерживая и откладывая их проявление на неопределенный срок.

Процесс выявления и развития талантов начинается еще с раннего детства и позволяет раскрыть определенные навыки до достижения зрелого возраста. Для обеспечения планомерного становления и развития высококвалифицированных сотрудников, профессионалов в конкретных областях важно системно использовать процесс управления талантами, основываться на преемственности «школа - вуз - трудоустройство-повышение квалификации». В решении такой фундаментальной задачи должно участвовать также государством посредством разработки и реализации государственных программ, предусматривающих мероприятия по поддержке талантливой молодежи.

Результаты данного исследования могут быть полезны для теоретиков и практиков при дальнейшем изучении вопроса развития талантов у молодежи, а также при построении системы управления талантами на уровне организаций и на национальным уровне.

\section{ПРИМЕЧАНИЕ}

${ }^{1}$ Авторы выражают благодарность студентам Российского университета дружбы народов (RUDN University) за активное участие в опросе, результаты которого были включены в данную статью. 


\section{СПИСОК ЛИТЕРАТУРЫ}

Иванова, С. Развитие потенциала сотрудников. Профессиональные компетенции, лидерство, коммуникации / С. Иванова, Д. Белдогоев. - М. : Альпина Паблишер, 2018. - 284 с.

Ильин, Е. П. Психология творчества, креативности, одаренности / Е. П. Ильин. - СПб., 2010. Электрон. текстовые дан. - Режим доступа: http://psychol.strategy48.ru/sites/default/files/ p_book/4.pdf (дата обращения: 12.03.2019).Загл. с экрана.

Искусство управления персоналом. Таланты и лидеры. Кн. 1 / Н. Черепухина [и др.]. - М. : Издво А. Капусты, 2002. -300 с.

Майклз, Э. Война за таланты/Э. Майклз, Х. ХэндфилдДжонс, Э. Экселрод ; пер. с англ. Ю. Е. Корнилович. - М. : Манн, Иванов и Фербер, 2005. - Электрон. текстовые дан. - Режим доступа: http:// consult-dnd.com.ua/d/741334/d/mayklz-voyna-zatalanty.pdf(дата обращения: 10.04.2019). - Загл. с экрана.

Марыскин, Д. 36 стратагем для руководителя \& 5 талантов, или Как найти работника своей мечты / Д. Марыскин. - М. : Издательские решения, 2017. - $74 \mathrm{c.}$

Мизинцева, М. Ф. Основные прогнозы развития рынка труда в мире / М. Ф. Мизинцева, А. Р. Сардарян, А. А. Петроченко// Российское предпринимательство. - 2017. - Т. 18, № 22. - С. 36373654.-DOI: $10.18334 /$ rp.18.22.38509.

Орт, М. Управление талантами / М. Орт, М. Эффрон. - М. : Азбука Бизнес, 2014. - 224 с.

Петроченко, А. А. Ключевые компетенции талантливых сотрудников на современном рынке труда / А. А. Петроченко // Социально ориентированное управление в условиях глобализации : материалы Всерос. науч.-практ. конф. М. : РУДН, 2018. - С. 288-293.

Питерс, Т. Дж. Основы. Талант / Т. Дж. Питерс. СПб. : Изд-во Стокгольм. шк. в Санкт-Петербурге, 2006. - 160 с.

Робертсон, А. Управление талантами. Как извлечь выгоду из таланта ваших подчиненных / А. Робертсон, Г.Эбби. -М. : Баланс-клуб, 2004. - 184 с.

Хэндфилд-Джонс, Х. Война за таланты / Х. Хэндфилд-Джонс, Э. Экселрод. - М. : Манн, Иванов и Фербер, 2011. - 280 c.

Chhabra, N. Talent Management and Employer Branding: Retention Battle Strategies / N. Chhabra, A. Mishra // ICFAI Journal of Management Research. 2008. - Vol. 7, № 11. - P. 50-61.

Dries, N. The Psychology of Talent Management: A Review and Research Agenda / N. Dries // Human Resource Management Review. 2013. - № 23 (4). - P. 272-285.
Hana, U. Investigating Talent Management Philosophies / U. Hana, V. Lucie // Journal of Competitiveness. - 2015. - № 7 (3). - P. 3-18.

Meyers, M. C. Talent-Innate or Acquired? Theoretical Considerations and Their Implications for Talent Management / M. C. Meyers, M. Van Woerkom, N. Dries // Human Resource Management Review. - 2013. - № 23 (4). - P. 305-321.

Swailes, S. Conceptualising Inclusive Talent Management: Potential, Possibilities and Practicalities / S. Swailes, Y. Downs, K. Orr // Human Resource Development International. 2014. - № 17 (5). - P. 529-544.

\section{REFERENCES}

Ivanova S., Beldogoev D. Razvitie potentsiala sotrudnikov. Professionalnye kompetentsii, liderstvo, kommunikatsii [Staff Capacity Development. Professional Competence, Leadership, Communication]. Moscow, Alpina Pablisher, 2018.284 p.

Ilyin E.P. Psikhologiya tvorchestva, kreativnosti, odarennosti [Psychology of Creativity, Giftedness]. Saint Petersburg, 2010. URL: http:// psychol.strategy48.ru/sites/default/files/ p_book/4.pdf (accessed 12 March 2019).

Cherepukhina N., Navruzov Yu. et al. Iskusstvo upravleniya personalom. Talanty $i$ lidery. Kniga 1 [Art of Personnel Management. Talents and Leaders. Book 1]. Moscow, Iz-vo A. Kapusty, 2002.300 p.

Majklz E., Hendfild-Dzhons X., Ekselrod E. Voyna za talanty [War for Talent]. Moscow, Mann, Ivanov i Ferber, 2005. URL: http:// consult-dnd.com.ua/ d/741334/d/mayklz-voyna-za-talanty.pdf (accessed 10 April 2019).

Maryskin D. 36 stratagem dlya rukovoditelya \& 5 talantov, ili Kak nayti rabotnika svoey mechty [36 Stratagems for Executive \& 5 Talents, or How to Find Your Dream Employee]. Moscow, Izdatelskie resheniya Publ., 2017. 74 p.

Mizintseva M.F., Sardaryan A.R., Petrochenko A.A. Osnovnye prognozy razvitiya rynka truda $\mathrm{v}$ mire [The Main Forecasts of the Labor Market in the World]. Rossiyskoe predprinimatelstvo [Russian Journal of Entrepreneurship], 2017, vol. 18 , no. 22 , pp. 3637-3654. DOI: $10.18334 /$ rp.18.22.38509.

Ort M., Effron M. Upravlenie talantami [Talent Management]. Moscow, Azbuka Biznes Publ., 2014. 224 p.

Petrochenko A.A. Klyuchevye kompetentsii talantlivykh sotrudnikov na sovremennom rynke truda [Key Competencies of Talented Employees 
in the Modern Labor Market]. Sotsialno orientirovannoe upravlenie $v$ usloviyakh globalizatsii: materialy Vserossiyskoy nauchno-prakticheskoy konferentsii [Socially Oriented Management in the Conditions of Globalization: Proceedings of the All-Russian Scientific and Practical Conference]. Moscow, Rossiyskiy universitet druzhby narodov, 2018, pp. 288-293.

Piters T.G. Osnovy. Talant [The Basics. Talent]. SaintPetersburg, Izd-vo Stokgolmskoy shkoly v Sankt-Peterburge, 2006. 160 p.

Robertson A., Ebbi G. Upravlenie talantami. Kak izvlech vygodu iz talanta vashikh podchinennykh [Talent Management. How to Benefit from the Talent of Your Subordinates]. Moscow, Balans-klub Publ., 2004. 184 p.

Hendfild-Dzhons H., Ekselrod E. Voyna za talanty [War for Talent]. Moscow, Mann, Ivanov i Ferber Publ., 2011. 280 p.
Chhabra N., Mishra A. Talent Management and Employer Branding: Retention Battle Strategies. ICFAI Journal of Management Research, 2008, vol. 7, no. 11, pp. 50-61.

Dries, N. The Psychology of Talent Management: A Review and Research Agenda. Human Resource Management Review, 2013, no. 23 (4), pp. 272-285.

Hana, U., Lucie V. Investigating Talent Management Philosophies. Journal of Competitiveness, 2015, no. 7 (3), pp. 3-18.

Meyers, M.C., Van Woerkom M., Dries N. Talent Innate or Acquired? Theoretical Considerations and Their Implications for Talent Management. Human Resource Management Review, 2013, no. 23 (4), pp. 305-321.

Swailes, S., Downs Y., Orr K. Conceptualising Inclusive Talent Management: Potential, Possibilities and Practicalities. Human Resource Development International, 2014, no. 17 (5), pp. 529-544.

\section{Information About the Authors}

Mariya F. Mizintseva, Doctor of Sciences (Economics), Professor, Head of the Department of Scientific Information on Economics and Management, All-Russian Institute for Scientific and Technical Information of the Russian Academy of Sciences, Usievicha St., 20, 125190 Moscow, Russian Federation, mfmizin@mail.ru, https://orcid.org/0000-0002-1276-2753

Anna R. Sardaryan, Candidate of Sciences (Economics), Associate Professor, Senior Researcher, Department of Scientific Information on Economics and Management, All-Russian Institute for Scientific and Technical Information of the Russian Academy of Sciences, Usievicha St., 20, 125190 Moscow, Russian Federation, gaviota21@mail.ru, https://orcid.org/0000-0002-7406-3149

Mariya A. Chugrina, Researcher, Department of Scientific Information on Economics and Management, All-Russian Institute for Scientific and Technical Information of the Russian Academy of Sciences, Usievicha St., 20, 125190 Moscow, Russian Federation, mariya-chavykina@mail.ru, https://orcid.org/0000-0002-2260-5663

\section{Информация об авторах}

Мария Федоровна Мизинцева, доктор экономических наук, профессор, заведующая отделом научной информации по экономике и управлению, Всероссийский институт научной и технической информации РАН, ул. Усиевича, 20, 125190 г. Москва, Российская Федерация, mfmizin@mail.ru, https://orcid.org/0000-0002-1276-2753

Анна Романовна Сардарян, кандидат экономических наук, доцент, старший научный сотрудник отдела научной информации по экономике и управлению, Всероссийский институт научной и технической информации РАН, ул. Усиевича, 20, 125190 г. Москва, Российская Федерация, gaviota21@mail.ru, https://orcid.org/0000-0002-7406-3149

Мария Александровна Чугрина, научный сотрудник отдела научной информации по экономике и управлению, Всероссийский институт научной и технической информации РАН, ул. Усиевича, 20, 125190 г. Москва, Российская Федерация, mariya-chavykina@mail.ru, https://orcid.org/0000-0002-2260-5663 